\title{
LA FAMILIA COMO DERECHO HUMANO
}

\author{
María Asunción GarCía MarTíneZ \\ Departamento de Derecho Constitucional \\ Facultad de Derecho \\ Universidad Complutense de Madrid \\ garciama@ucm.es
}

\begin{abstract}
RESUMEN
Se aborda el proceso de configuración de la familia, a partir de su concepción como institución social, como titular y objeto de derechos bumanos, lo que le dota de una dimensión y unos contenidos concretos garantizados por una protección constitucional y jurisprudencial especificos.
\end{abstract}

Palabras clave: derechos humanos, familia, derecho a la vida familiar, derecho a la intimidad familiar.

\section{ABSTRACT}

We bereby study the process of family shaping, from its perception as a social institution, as a bolder and subject to buman rights, which credits it with a scope and particular content toward a specific constitutional and case law protection.

Keywords: Human rights, family, right to a family right to a family privacy.

\section{ZUSSAMENFASSUNG}

Die vorliegende Arbeit umfasst den Prozess der Familiengestaltung, ausgehend vom Begriff der Familie als sozialer Institution, mit dem Ziel und Zweck eines Menschenrechts. Dadurch gewinnt der Begriff eine konkrete Dimension und konkrete verbürgte Inbalte, die spezifisch verfassungsrechtlich und gerichtlich geschützt werden.

Schlüsselwörter: Menschenrechte, Familie, Recht auf Familienleben, Recht auf familiäre Privatsphäre

SUMARIO: I. DERECHOS HUMANOS Y GLOBALIZACIÓN.-II. LA INSTITUCIÓN FAMILIAR Y LA GLOBALIZACIÓN. DE LA PROTECCIÓN DE LA FAMILIA A LA FAMILIA COMO DERECHO.-III. FAMILIA FORMAL, FAMILIA MATERIAL.-IV. LA FAMILIA COMO CONTENIDO DEL DERECHO: LOS DERECHOS A LA FAMILIA Y A LA VIDA FAMILIAR.-V. LA FAMILIA COMO TITULAR DEL DERECHO: EL DERECHO A LA INTIMIDAD FAMILIAR.—VI. CONCLUSIONES.—VII. ABREVIATURAS. 


\section{DERECHOS HUMANOS Y GLOBALIZACIÓN}

$\mathrm{Al}$ margen de la dimensión axiológica de los derechos humanos ${ }^{1}$, que es su fundamento ético y moral y el elemento imprescindible a la hora de articular un tratamiento coherente de los mismos, de su razón de ser, de sus límites y de sus garantías, su categoría histórica les vincula a unos contextos concretos y variables, dominados por los modelos culturales imperantes, y es esta trayectoria histórica la que, en respuesta a la naturaleza dinámica de los derechos, ha configurado de forma progresiva su estructura actual.

La diferencia que establecía Benjamin Costant entre la libertad de los antiguos y la de los modernos pone de relieve el proceso de conceptualización de los derechos en el mundo occidental; frente al modelo del mundo clásico en el que los derechos solo correspondían a la persona en su condición de ciudadano, la libertad de los modernos los atribuye a las personas en su condición de seres individuales dotados de igual dignidad. La trayectoria que lleva a esta conclusión parte del pensamiento cristiano, se encarna en la escuela iusnaturalista en la Edad Media y desemboca con el humanismo renacentista en un nuevo iusnaturalismo, no necesariamente cristiano, que tendrá su pleno desarrollo en el siglo XVIII, en cuyo contexto culminará la construcción del iusnaturalismo racionalista en el que se fundamentará en buena parte el sustrato ideológico y legitimador del Estado constitucional, que al plasmar los derechos en textos escritos, que progresivamente sustituyen su denominación de derechos naturales por la de derechos del hombre, les va a dotar de una dimensión nueva y desconocida hasta entonces.

La positivación de los derechos, primero en las declaraciones y posteriormente en las constituciones, supone su modificación cualitativa, al ser revestidos de una doble dimensión en virtud de las funciones que cumplen en la esfera jurídico-política; los derechos humanos adquieren así una dimensión objetiva de legitimación del sistema político y otra subjetiva en su función de protección y garantía, que se traduce en la tutela de la libertad, la seguridad y la autonomía de la persona frente al Estado y frente a los particulares.

En esta mínima referencia a la trayectoria histórica de los derechos se detecta la pauta de evolución dinámica que ha sido siempre característica básica de las relaciones sociales; su dinamismo, que ha podido ser más

\footnotetext{
${ }^{1}$ R. Alexy, Teoría de los derechos fundamentales, Madrid, Centro de Estudios Políticos y Constitucionales, 2007, pp. 84 y ss.
} 
o menos acusado, más o menos rápido, es un elemento indisociable de la vida social y, de hecho, la trayectoria de los grandes movimientos sociales, económicos, culturales, políticos y jurídicos reflejan de forma permanente la evolución de los valores de toda índole que han ido sustentando los modelos asumidos en el mundo occidental. Esta constante evolutiva adquiere en la actualidad una dimensión totalmente diferente, con rasgos cuantitativa y cualitativamente propios, en la medida en que se insertan en el proceso de la globalización o mundialización, que constituye una nueva etapa — que no será la última - de dicho proceso.

La diferencia clave respecto de las etapas anteriores es su aceleración gracias a la rápida y amplia intercomunicación que propician las nuevas tecnologías de la información y de la comunicación, que, sometidas a su vez a una progresión que parece no tener límites, impulsan de forma incansable la modificación de buena parte de los valores tradicionales y su sustitución por otros de nuevo cuño, no constreñidos por los límites nacionales. Ni la interrelación ni la intercomunicación son fenómenos nuevos, lo que es nuevo es la aceleración y la dimensión que ha adquirido el proceso como resultado de la revolución digital que nos han llevado a la llamada «aldea global».

El fenómeno al que aludimos surge en el ámbito de la economía y de los mercados ${ }^{2}$, pero supera su origen y casi de forma simultánea se proyecta en todos los ámbitos en los que se desarrolla la vida humana, configurando espacios sociales y políticos nuevos entre los que necesariamente se encuentra y se ve afectado el Estado constitucional ${ }^{3}$, y, por supuesto, no podría desvincularse de su influencia el mundo de los derechos humanos. La expansión de la necesidad no ya del reconocimiento de los derechos y libertades, sino también de sus garantías para hacerlos efectivos, no se limita a la conciencia de su funcionalidad como elementos legitimadores, sino que se proyecta en la expansión de los ámbitos geográficos de su afirmación y garantía, en la ampliación de los contenidos de los derechos tradicionales y en la configuración de nuevos derechos, con frecuencia a partir de la transformación de valores sociales y culturales que desemboca en la formulación de derechos en respuesta a nuevas formas de apreciar instituciones y derechos preexistentes.

2 J. L. SAMPEDRO, El mercado y la globalización, Barcelona, Destino, 2002, p. 65.

3 P. DE Vega García, «Mundialización y Derecho constitucional: la crisis del principio democrático en el constitucionalismo actual», en R. RuBIo NúÑEZ (ed.), Obras escogidas de Pedro de Vega García, Madrid, Centro de Estudios Políticos y Constitucionales, 2017, pp. 294 y ss. 
El inicio del proceso de mundialización de los derechos podría determinarse en el momento en que se supera el ámbito nacional y se pasa de su constitucionalización a su internacionalización al ser consagrados en textos internacionales o supranacionales y garantizados por órganos jurisdiccionales de ámbito supranacional. Entre otros, el Convenio Europeo de Derechos Humanos de 1950 (en adelante, CEDH), la Carta Social Europea de 1966 y la Carta de Derechos Fundamentales de la Unión Europea (aprobada en Niza en el año 2000 e incorporada como derechos de la Unión Europea al Tratado de Lisboa) se asientan sobre la idea de que la comunidad supranacional puede entender de cuestiones que afecten no tanto a los Estados, sino, sobre todo, a los derechos de sus ciudadanos ${ }^{4}$. En consecuencia, se establecen una serie de órganos jurisdiccionales de ámbito supranacional [Tribunal Europeo de Derechos Humanos (en adelante, TEDH) y Tribunal de Justicia de la Unión Europea (en adelante TJUE)] ante los que los ciudadanos de los Estados adheridos al CEDH o miembros de la Unión Europa pueden ejercer sus acciones individuales frente a las violaciones de sus derechos no atendidas por los respectivos Estados. La Convención Americana de Derechos Humanos de 7 de abril de 1970 (San José de Costa Rica) proyecta la misma filosofía en los países americanos adheridos, siendo la Corte Interamericana de Derechos Humanos y la Comisión Interamericana de Derechos Humanos (en adelante, CIDH) los organismos de aplicación y garantía de la citada Convención.

Estos textos, con la garantía jurisdiccional que incorporan, suponen un paso decisivo en el devenir de los derechos humanos al considerarlos parte integrante de la identidad supranacional correspondiente (europea y latinoamericana) fundamentada en una voluntad política común de conceptualización y protección de los derechos. La proliferación de textos de carácter internacional, supranacional o regional es un rasgo característico del proceso de globalización, en la medida en que pretende devenir en una concepción atemporal y ahistórica de los derechos al formular un mínimo común de los estándares de protección ${ }^{5}$, por debajo de los cuales la comu-

${ }^{4}$ J. CORCUERA ATIENZA, «El reconocimiento de los derechos fundamentales en la Unión Europea», en R. Morodo y P. DE Vega (dirs.), Estudios de la teoría del Estado y Derecho constitucional en honor de Pablo Lucas Verdú, t. IV, México DF-Madrid, Instituto de Investigaciones Jurídicas de la Universidad Nacional Autónoma de México-Servicio de Publicaciones de la Facultad de Derecho de la Universidad Complutense de Madrid, 2001, pp. 2307 y ss.

5 A. SÁnCHez LegIDO, La reforma del mecanismo de protección del Convenio Europeo de Derechos Humanos, Madrid, Colex, 1995, pp. 96 y ss., y A. QueRALT JimÉNEZ, La interpretación de los derechos: del Tribunal de Estrasburgo al Tribunal Constitucional, Madrid, Centro de Estudios Políticos y Constitucionales, 2008, pp. 98-101. 
nidad internacional estima que no se respetan los mismos. Se afirma así una cierta universalidad de los derechos al establecer un núcleo común de valores indisponibles que integran, junto con la dimensión subjetiva de los derechos que proclaman, la proyección objetiva legitimadora, con la consecuencia de que la determinación de cuáles son los derechos fundamentales ya no es algo reservado exclusivamente al ámbito estatal ${ }^{6}$. En esta línea, tanto el preámbulo del CEDH como el art. 6 del Tratado de la Unión Europea (en adelante, TUE) afirman el Estado de Derecho (prééminece du droit; rule of law) como uno de sus núcleos esenciales, asociado a «una concepción y un respeto comunes de los derechos humanos» ${ }^{7}$, lo que convierte a estos textos y a los derechos que proclaman, en los términos del TEDH, refiriéndose en concreto al CEDH, en «instrumento del orden público europeo» ${ }^{8}$.

No puede ignorarse que la tutela multinivel de los derechos genera una problemática específica respecto de la relación entre los ordenamientos constitucionales y los textos internacionales o supranacionales de reconocimiento y garantías de derechos ${ }^{9}$; problemática que incluye el ámbito de influencia de la interpretación de los derechos dada por los órganos jurisdiccionales supranacionales en los nacionales. Sin embargo, pese a las disfuncionalidades y exigencias que pudieran derivarse de los diferentes ratios de interpretación y distintos niveles de garantía de los

${ }^{6}$ J. C. BAYÓn, «El constitucionalismo en la esfera pública global», Anuario de Filosofía del Derecho, núm. 29 (2013), pp. 57-99, en concreto pp. 69 y 70, y J. GARCíA RocA, «La interpretación constitucional de una declaración internacional, el Convenio Europeo de Derechos Humanos, y bases para una globalización de los derechos», Revista Europea de Derechos Fundamentales, núm. 6 (2005), pp. 37-82.

${ }^{7}$ L. Jimena QueSADA, «La europeización del Estado de Derecho (reflexiones a la luz de la realidad político-constitucional española)», en R. MORODO y P. DE VEGA (dirs.), Estudios de la teoría del Estado y Derecho constitucional en honor de Pablo Lucas Verdú, t. IV, México DF-Madrid, Instituto de Investigaciones Jurídicas de la Universidad Nacional Autónoma de México-Servicio de Publicaciones de la Facultad de Derecho de la Universidad Complutense de Madrid, 2001, pp. 2341-2378, en concreto p. 2343.

8 STEDH de 23 de marzo de 1995, caso Loizidou c. Turquía. Vid. también J. García RocA, «El preámbulo, contexto hermeneútico del Convenio: un instrumento constitucional del orden público europeo», en J. García Roca y P. SANTOLAYA (dirs.), La Europa de los derechos. El Convenio Europeo de Derechos Humanos, Madrid, Centro de Estudios Políticos y Constitucionales, 2009, pp. 25-27.

9 J. GARCÍA ROCA, «La interpretación constitucional de una declaración internacional, el Convenio Europeo de Derechos Humanos, y bases para una globalización de los derechos», Revista Iberoamericana de Derecho Procesal Constitucional, núm. 5 (2006), pp. 139-182, y R. Canosa Usera, «La interpretación evolutiva del Convenio Europeo de Derechos Humanos», en J. GARCÍA ROCA y P. A. FeRnÁNDEZ (dirs.), Integración europea a través de derechos fundamentales: de un sistema binario a otro integrado, Madrid, Centro de Estudios Políticos y Constitucionales, 2009, pp. 79-112. 
derechos ${ }^{10}$, lo cierto es que la actividad desarrollada por los órganos jurisdiccionales supranacionales ha sido sin duda uno de los factores más significativos del proceso de globalización de los derechos humanos, lo que les ha convertido en uno de los motores de la expansión de los mismos ${ }^{11}$.

\section{LA INSTITUCIÓN FAMILIAR Y LA GLOBALIZACIÓN. DE LA PROTECCIÓN DE LA FAMILIA A LA FAMILIA COMO DERECHO}

La modificación de modelos culturales a niveles no alcanzados anteriormente, que es uno de los efectos de la globalización, ha supuesto abrir una serie de perspectivas distintas respecto de los derechos, entre las que cabe destacar la reafirmación de los derechos clásicos articulados con nuevos contenidos fruto de su aplicación por medio de criterios interpretativos más amplios junto a la aparición de derechos de nuevo cuño como consecuencia lógica de las realidades sociales que imponen los factores determinantes de la globalización. Buena parte de estos nuevos derechos nacen conectados o derivados de algunos de los tradicionales, si bien no faltan otros que derivan de instituciones sociales a través de su vinculación a derechos preexistentes, elevando a la categoría de derechos fundamentales lo que eran derechos subjetivo-privados de la personalidad ${ }^{12}$. Con ello se produce una mutación de su naturaleza originaria en la medida en que, sin dejar de ser instituciones, pasan a ser derechos, lo que se proyecta necesariamente en alteraciones, a veces sustanciales, de sus contenidos institucionales clásicos.

En este último aspecto son paradigmáticos los cambios producidos en las estructuras familiares que han derivado en un proceso de auténtica reconversión de una de las instituciones sociales básicas, la familia, en derecho humano, tanto en su condición de contenido como de titular del mismo. En este proceso ha contribuido como factor esencial, además de la ya mencionada modificación de los modelos culturales y su rápida e imparable expansión hoy por hoy en el mundo occidental, la jurisprudencia de

${ }^{10}$ J. C. BAYÓN, «El constitucionalismo en la esfera pública global», op. cit., pp. 80 y ss.

11 A. Queralt JiméNez, El Tribunal de Estrasburgo: una jurisdicción internacional para la protección de los derechos fundamentales, Valencia, Tirant lo Blanch, 2003, pp. 68 y 69, y F. SuDRE, Droit européen et internationel des droits de l'homme, París, Presses Universitaires de France, 2005, p. 133.

${ }^{12}$ C. Sempere Rodríguez, «Comentario al art. 18», en Ó. Alzaga Villaamil (dir.), Comentarios a la Constitución de 1978, Madrid, Edersa-Cortes Generales, 1997, p. 386. 
los tribunales supranacionales de garantía de los derechos humanos, básicamente el TEDH y la CIDH, que ha registrado, y en no pocas ocasiones impulsado, aquellos nuevos estándares culturales asumidos frecuentemente por los órganos jurisdiccionales nacionales, dada la capacidad de arrastre de aquella jurisprudencia. Pese a la diferencia cuantitativa de las decisiones del Tribunal de Estrasburgo y de la Corte de San José, que se creó y empezó su actividad bastante después, la intensa interrelación entre ambos ha configurado un cuerpo de doctrina prácticamente uniforme deducida de la aplicación de criterios interpretativos muy similares ${ }^{13}$, lo que no deja de ser un nuevo factor de globalización de los derechos.

La familia es una de las realidades sociales más antiguas del mundo. Su importancia social y la pluralidad de funciones que ha desempeñado tradicionalmente como grupo humano ligado a la subsistencia de la sociedad la ha configurado como una institución que ha sido siempre objeto de interés público y, en consecuencia, de regulación jurídica. Sus dos finalidades sociales básicas, ámbito estable de nacimiento de nuevos ciudadanos y elemento primario de formación y desarrollo de la personalidad y de socialización de sus miembros que permite, en definitiva, la integración de los individuos en el cuerpo social, las asume la familia al margen del modelo que social y culturalmente se plantee en cada momento histórico (familia patriarcal, matriarcal, reducida, extensa, de base monogámica, poligámica, poliándrica...). No existe ni ha existido nunca un único modelo de familia intemporal, ya que son las estructuras sociales, culturales y económicas concretas las que han determinado el modelo familiar adecuado a los fines y funciones específicas a desarrollar en cada sociedad, pero cualquiera que sea el modelo predominante es la dimensión pública de la institución familiar la que determina tanto su relevancia jurídica cuanto que su regulación integre el interés del poder público.

La protección de la familia por los poderes públicos alcanza categoría constitucional en el contexto del Estado social, que asume que la familia es objeto de la obligación prestacional que tienen aquellos poderes. Su inclusión en el ámbito de los derechos sociales se proyecta en el reconocimiento de una discrecionalidad, más o menos amplia, de los poderes públicos respecto del contenido de aquellas obligaciones constitucionalmente debidas a la familia.

13 J. García Roca, H. Nogueira Alcalá y R. Bustos Gisbert, «La comunicación entre ambos sistemas y las características del diálogo», en J. GarCía RoCA, P. A. FERnándeZ y R. CANOSA (dirs.), El diálogo entre los sistemas europeo y americano de derechos bumanos, Madrid, Civitas, 2012, pp. 79-88. 
A partir del mandato constitucional de «protección a la familia», asumido en su momento por los textos supranacionales, se pasará al reconocimiento de una serie de derechos de carácter personal vinculados a la familia (derecho a formar una familia, derecho a la vida familiar...), y de aquí a la construcción de derechos cuyo titular ya es la misma familia (derecho a la intimidad familiar) o la persona en su condición de miembro de una familia (derecho a la vida familiar, derecho al nombre familiar, a la investigación de la paternidad...), superando así el concepto prestacional de los derechos sociales al integrar como protección de la familia derechos no configurados en origen con esta finalidad, pero que al vincularse con aquel objetivo han visto ampliado su contenido. Los derechos al desarrollo de la personalidad, a la inviolabilidad del domicilio o a la intimidad, entre otros, concebidos como derechos personales, en el momento en que se proyectan sobre la familia adquieren una dimensión social que supera el marco individualista originario.

La articulación de la familia como derecho se ha sustanciado sobre una serie de derechos preexistentes, fundamentalmente derechos personales, de donde deriva la atribución al nuevo derecho de las cualidades propias de los derechos como mandatos de protección frente a los poderes públicos y en las relaciones privadas. De aquí, además de su configuración como auténtico derecho subjetivo que otorga facultades concretas a sus titulares, entre ellas las de su defensa frente a la vulneración del derecho, la obligación de que las limitaciones al derecho deban tener carácter restrictivo además de la inclusión del principio de ponderación en los supuestos de colisión con otros derechos.

Dado que el reconocimiento de la familia, tanto como contenido cuanto como titular de derechos, es tardío respecto de otros derechos, su configuración es en buena parte deudora de la jurisprudencia de los tribunales, nacionales y supranacionales, a partir de su articulación, a veces de forma incipiente, en los textos normativos. La pauta evolutiva, con estar generalizada, no se desarrolla e implanta al mismo ritmo en cada Estado. La institución familiar configura el núcleo social de un Estado, de forma que en su evolución inciden de forma muy significativa los modelos culturales, más o menos tradicionales, de cada sociedad, por lo que no existe una trayectoria simultánea, que dependerá del arraigo más o menos fuerte de los modelos sociales más conservadores, con la consecuencia de que la aceptación de los nuevos conceptos está supeditada a aquellos modelos y valores, si bien, al menos en el mundo occidental, el proceso se presenta, antes o después, como incuestionable. 


\section{FAMILIA FORMAL, FAMILIA MATERIAL}

El modelo tradicional de familia en la sociedad occidental ha respondido a un concepto formal, socialmente aceptado y jurídicamente regulado e identificado con la familia matrimonial, definida como un grupo de personas unidas entre sí por los vínculos derivados de la conyugalidad y el parentesco, ya sea consanguíneo, de adopción o de afinidad. La interdependencia histórica entre el matrimonio - en cualquiera de sus formas de celebración como causa causandi formal - y la familia es tan evidente que los demás modelos de familia se singularizan en relación con la matrimonial y tan clásica que la regulación y protección jurídica de la familia la ha monopolizado la matrimonial, incluidas las fórmulas constitucionales que consagran simultáneamente familia y matrimonio. Sirvan como ejemplo los arts. 29 de la Constitución italiana, 6 de la Ley Fundamental de Bonn o 36 de la Constitución portuguesa de 1976. Como una excepción en este panorama, la Constitución española de 1978 diferencia el derecho al matrimonio de la protección de la familia con fórmulas autónomas; el derecho al matrimonio se consagra como derecho fundamental (art. 32.1), mientras que la mención a la familia se incluye en los llamados «principios rectores de la política social y económica» (art. 39), al tiempo que se reconocen una serie de derechos fundamentales que dan una categoría constitucional a la protección de la familia [derecho a la intimidad familiar (art. 18), derecho a la educación (art. 27) e incluso los apartados 2 y 3 del mismo art. 39]. Con ello la CE desvincula a la familia de la familia matrimonial configurando el derecho a su protección aplicable a otros modos de convivencia, matrimonial o no matrimonial, si bien parece dudoso que los constituyentes de 1978 tuvieran en mente esta desconexión, difícilmente concebible en aquel momento.

También los textos internacionales recurren mayoritariamente al tratamiento conjunto de los derechos al matrimonio y a la familia, tal y como resulta en la Declaración Universal de Derechos del Hombre de 1948 (art. 16.1), en el Pacto Internacional de Derechos Civiles y Políticos (art. 23.2), en el Convenio Europeo de Derechos Humanos (art. 12) y en la Convención Americana de Derechos Humanos (art. 17.2). Incluso en fecha más reciente la Carta de los Derechos Fundamentales de la Unión Europea de 2002 opta también por vincular ambos derechos (art. 9).

Esta interconexión social y normativa entre familia y matrimonio se rompe en buena parte como resultado de la incidencia que ha tenido en la 
preeminencia casi absoluta del modelo de familia matrimonial la alteración sustancial de dos de los elementos del matrimonio, la titularidad del derecho y la finalidad de la procreación como una de sus funciones primarias, lo que ha contribuido de forma decisiva a la modificación del significado del derecho a contraer matrimonio, cuyo contenido básico sigue siendo indisponible para los cónyuges, y a las mutaciones producidas en la institución familiar y en su afirmación como derecho.

La titularidad del derecho a contraer matrimonio ha sido siempre del hombre y de la mujer, resultando la exigencia de la heterosexualidad absolutamente lógica cuando uno de sus principales fines sociales (no solo personales) es la procreación en una estructura estable, determinante de su función social. El matrimonio heterosexual era tan evidente hasta el último tercio del siglo Xx que, como hemos indicado, tanto los textos constitucionales como los internacionales lo dan por sobreentendido y ni se plantean la cuestión. No hay un único factor responsable de la profunda modificación de esta «imagen maestra»; confluyen una nueva dimensión de determinados derechos, entre ellos y de forma significativa la valoración como derecho del desarrollo de la personalidad y a la no discriminación, junto a unos adelantos médicos y científicos que han abierto unas opciones impensables hace no demasiados años, tanto respecto del cambio de sexo como en relación con la procreación natural como única opción, que hoy hay que combinar con las amplias posibilidades que ofrecen las diversas técnicas de reproducción asistida, in vitro, etc. El matrimonio no ha sido inmune a la avalancha de cambios que han invadido de forma rápida y progresiva todos los ámbitos sociales, culturales y jurídicos, y que han afectado a lo que parecía inmutable, con el resultado de la progresiva expansión del reconocimiento normativo del matrimonio entre personas del mismo sexo en abierta contradicción con la exigencia tradicional de la heterosexualidad, con la proyección que ello ha supuesto a la hora de constituir nuevas estructuras familiares.

La jurisprudencia del TEDH ha sido sin duda uno de los factores determinantes del cambio, por lo que parece obligado hacer una somera referencia a su evolución en un periodo de más o menos treinta años que ha desembocado, a partir de la apreciación de la proyección de la transexualidad sobre los derechos personales de los recurrentes, en una nueva percepción del derecho al matrimonio ${ }^{14}$, en la que, entre otras cuestiones, prima la valoración personalista de los contrayentes sobre su fin social y procreador.

14 A. Torres Gutiérrez, «El derecho a contraer matrimonio (art. $12 \mathrm{CEDH}$ )», en J. García Roca y P. Santolaya (dirs.), La Europa de los derechos. El Convenio Europeo 
En un principio, la problemática que se le plantea al TEDH es la de las personas transexuales que solicitan el reconocimiento jurídico de su nuevo sexo ${ }^{15}$, en algunos casos para poder contraer matrimonio con personas de sexo opuesto al recién adquirido, lo que les resulta imposible, ya que, al no permitir la legislación nacional la modificación registral respecto del sexo, la unión sería oficialmente entre personas del mismo sexo biológico, no admitida por el Estado correspondiente. Todas las sentencias resuelven no contraria al art. $12 \mathrm{CEDH}$ la normativa matrimonial nacional, entendiendo que el citado precepto hace referencia al matrimonio entre personas de sexo biológico opuesto porque su finalidad es proteger el matrimonio en cuanto fundamento de la familia ${ }^{16}$.

El cambio de criterio se hace evidente en dos Sentencias de 11 de julio de 2002 (casos Christine Goodwin c. Reino Unido ${ }^{17}$ e I. c. Reino Unido) en las que la Gran Sala aprecia por unanimidad contradicción entre la normativa nacional y el art. $12 \mathrm{CEDH}$, dando un giro radical a su jurisprudencia. El tribunal descarta el criterio biológico como elemento decisivo para excluir a determinadas personas del derecho a contraer matrimonio y fundamenta su decisión en la consideración de la transexualidad como factor discriminatorio. La obligación de los Estados de proteger la seguridad física y moral de los transexuales impone una interpretación de la no discriminación afirmada en el art. $14 \mathrm{CEDH}$ no solo como igualdad formal o ante la ley, sino como igualdad material ${ }^{18}$.

El abandono como argumento de las técnicas médicas y biológicas que permiten el cambio de sexo, válido solo en el caso de los transexuales, abre la posibilidad de aplicar el mismo argumento de la discriminación respec-

de Derechos Humanos, Madrid, Centro de Estudios Políticos y Constitucionales, 2009, pp. 553 y ss.

${ }_{15}$ Casos van Oosterwijck c. Bélgica (27 de febrero de 1980), Rees c. Reino Unido (17 de octubre de 1986), Cossey c. Reino Unido (29 de septiembre de 1990) y Sheffied y Horsham c. Reino Unido (30 de julio de 1998).

16 Aunque el fallo es similar, el caso Rees se aprueba por unanimidad, mientras que en el caso Cossey, solo cuatro años después, hay cuatro votos discrepantes; el del juez Martens anticipa los argumentos del posterior cambio de postura del TEDH.

${ }_{17}$ Es significativo que en este caso, a diferencia de otros anteriores que se denominan solo con el apellido del demandante, se incluya el nombre, femenino, de la demandante, transexual nacido con género masculino, con el que el TEDH adelanta ya su fallo.

${ }_{18}$ E. Carmona Cuenca, «La prohibición de discriminación (art. 14 CEDH y Protocolo 12)», en J. García Roca y P. Santolaya (dirs.), La Europa de los derechos. El Convenio Europeo de Derechos Humanos, Madrid, Centro de Estudios Políticos y Constitucionales, 2009, p. 588. Este criterio lo aplica el TEDH en los casos van Kück c. Alemania (12 de septiembre de 2003) y Grant c. Reino Unido (23 de mayo de 2006). 
to de los homosexuales ${ }^{19}$, cuestión que finalmente plantea abiertamente el TEDH en la Sentencia de 24 de junio de 2010, caso Schalk y Kopf c. Austria, en la que resume su doctrina en relación con el matrimonio entre personas del mismo sexo: «El art. 12 [del $\mathrm{CEDH}]$ garantiza el derecho fundamental del hombre y la mujer a casarse y fundar una familia», constatando que aunque el Tribunal «no ha tenido aún la oportunidad de examinar si dos personas del mismo sexo pueden reclamar el derecho a casarse [....] pueden deducirse algunos principios de su jurisprudencia en materia de transexualidad». Por último, el TEDH reconoce que en el caso Christine Goodwin «se apartó de esta jurisprudencia [tradicional], considerando que los términos del art. 12, que hacen referencia al derecho del hombre y la mujer a contraer matrimonio, no podían entenderse ya como determinantes del género con arreglo a criterios puramente biológicos». La conclusión es que el art. $12 \mathrm{CEDH}$ no impone a los Estados la obligación de admitir el matrimonio entre personas del mismo sexo, pero la opción de su admisión es válida y conforme al Convenio, con lo que el Tribunal de Estrasburgo parece estar sugiriendo a los Estados cuál es su opción preferente ${ }^{20}$.

Aunque el TEDH parece atribuirse una función de correa de transmisión de una «tendencia internacional continuada» de aceptación de la transexualidad y del matrimonio homosexual, cabe preguntarse si su rol no ha superado esta relativa modesta función ${ }^{21}$. En nuestra opinión, la influencia de su jurisprudencia es difícilmente cuestionable desde el momento en que ha asentado los fundamentos jurídicos del derecho a la identidad sexual y del derecho a contraer matrimonio en una serie de derechos humanos preexistentes directamente inherentes a la dignidad del hombre, articulando de esta manera los mimbres sobre los que, como una ola expansiva, los ordenamientos estatales, e incluso supraestatales, irán modificando sus respectivas regulaciones para incluir la opción del derecho al matrimonio entre personas del mismo sexo ${ }^{22}$, que es sin duda un factor verdaderamente revolucionario en la línea de flotación tradicional de una institución ancestral.

${ }^{19}$ F. SUdRE, Droit européen..., op. cit., p. 423.

${ }^{20}$ En el ámbito de la Unión Europea, el TJUE coincide con el criterio de no imposición de la regulación del matrimonio homosexual, pero impone la obligación de todos los Estados miembros de reconocer estos matrimonios contraídos en cualquier otro Estado de la UE (caso C-673/16, STJUE de 15 de junio de 2018).

${ }^{21}$ F. Sudre, Droit européen..., op. cit., pp. 230- 232.

22 A. L. Calvo Caravaca y J. Carrascosa González, «El matrimonio entre personas del mismo sexo en la Unión Europea», Revista Crítica de Derecho Inmobiliario, núm. 700 (2007), pp. 443 y ss. 
Pese a su transcendencia, esta evolución no supone la desaparición del modelo formal de familia identificado con la matrimonial, ya que la posibilidad de que los contrayentes sean del mismo sexo no excluye la naturaleza matrimonial de la familia así constituida, al margen de la alteración que se pueda dar en los roles tradicionales. Sin embargo, no puede ignorarse que la aceptación social y jurídica del matrimonio entre personas del mismo sexo, junto con la pérdida de peso del matrimonio como hecho determinante de la familia, ha incidido de forma significativa en la evolución social y jurídica de la institución familiar, en la que nuevamente no es la jurisprudencia un factor indiferente ${ }^{23}$. La consolidación de nuevas formas familiares no vinculadas al matrimonio responde a la valoración de una serie de derechos específicos (el libre desarrollo de la personalidad, la no discriminación, la intimidad, la propia identidad sexual, etc.) que se proyecta en la valoración individualizada de los miembros de la familia respecto de su consideración grupal, lo que acaba determinando la opción de configurar una forma de convivencia acorde no ya con la libre orientación sexual, sino también con los derechos personalizados de cada uno de los miembros que integran la institución familiar; derechos que, aunque no estén en ocasiones reconocidos expresamente en los textos positivos, se derivan de un nuevo derecho, el derecho a formar y pertenecer a una familia. Sirva como ejemplo, entre otras, la Sentencia del CIDH de 1 de marzo de 2005, caso Hermanas Serrano Cruz c. El Salvador, en el que la Corte deriva el derecho a la identidad de las demandantes, no incluido en la $\mathrm{CADH}$, del derecho a la familia, ya que, afirma la sentencia, sin familia ni nombre no hay identidad ${ }^{24}$.

La «metamorfosis civilizadora» que sintetiza la profunda mutación del derecho a la familia ${ }^{25}$ se basa en el desplazamiento de la concepción grupal de la familia por la primacía del individualismo de los miembros que la integran y de sus derechos personales, entre los que hay que incluir, además de los ya citados, el de la igualdad. De esta manera, la «familia deseada» supone el triunfo de la voluntad sobre un modelo formal, al menos parcialmente obsoleto, abriendo paso a un concepto material de

${ }^{23}$ La resolución de la sentencia del TEDH del caso Schalk y Kopf se fundamenta no tanto en el derecho al matrimonio de la pareja demandante (del mismo sexo), sino en su derecho a la vida familiar.

${ }^{24}$ En el mismo sentido, SCIDH de 31 de agosto de 2011, caso Contreras c. El Salvador.

25 L. Burgorgue-LarSENN, «La jurisprudence des cours constitutionnelles européennes en droit des personnes et de la famille», Les nowveaux Cabiers du Conseil Constitutionnel, núm. 39 (2013), p. 229. 
familia ${ }^{26}$ que, sin desplazar el formal, amplía las formas familiares posibles. Así, se incluye en el concepto de familia cualquier relación en la que de hecho se generen lazos de mutua dependencia equivalentes a los contemplados jurídicamente, por alejados que resulten de los parámetros de la familia matrimonial. Estos nuevos modelos de familia no se articulan necesariamente sobre el parentesco, consanguíneo o de adopción, que puede o no existir, ya que en ellas no existen necesariamente ni la conyugalidad ni el parentesco de afinidad, sino sobre el deseo y la convivencia, valorada como un factor añadido y determinante, tal y como expresamente afirma la Sentencia del TEDH de 7 de febrero de 2002, caso Mikulic c. Croacia $^{27}$, y, en el mismo sentido, la Sentencia del CIDH de 24 de febrero de 2012, caso Atala Riffo y niñas c. Chile ${ }^{28}$. En definitiva, los requisitos jurídicos que revestían la voluntad de formar la familia formal han ido cediendo respecto de la familia material ante la constatación del hecho de la convivencia derivada de aquella voluntad.

A partir de la clasificación básica de familia, ya sea formal o material, los dos modelos han dado lugar a diversas combinaciones tanto en las familias monoparentales ${ }^{29}$ como en las reconstruidas derivadas de uniones sucesivas, matrimoniales o no matrimoniales ${ }^{30}$. La complejidad de relaciones familiares que pueden derivarse de estas nuevas formas pone de relieve la fluidez extraordinaria en las relaciones familiares actuales con supuestos que exceden de los previstos en las normativas tradicionales.

Desde el momento en que la familia matrimonial deja de ser el único modelo contemplado jurídicamente, la exigencia de la no discriminación se traduce en una equiparación jurídica de las distintas formas de estructurar la relación familiar ${ }^{31}$, si bien es necesario subrayar que la no discrimi-

${ }^{26}$ Ibid., p. 230.

${ }^{27}$ No es necesario que dos personas formalicen su relación para que exista una familia, basta la existencia de lazos personales estrechos.

28 «El concepto de vida familiar no está reducido únicamente al matrimonio, sino que debe abarcar otros lazos familiares de hecho donde las partes tienen vida en común fuera del matrimonio».

29 A las causas tradicionales de la familia monoparental (fallecimiento de uno de los progenitores, ruptura matrimonial o de la convivencia, desconocimiento de uno de los progenitores, adopción por un solo adoptante...) se añade la de la simple voluntad del progenitor/a.

${ }^{30}$ En este tipo de familias la conyugalidad puede o no existir, el parentesco por consanguinidad puede variar entre los distintos miembros de la familia y puede existir una parentalidad socioafectiva y una parentalidad sociológica de la que derivan derechos y obligaciones no vinculadas a la patria potestad.

31 El TC considera la existencia de modelos familiares no matrimoniales «como corresponde a una sociedad plural» (SSTC 222/1992 y 47/1993), afirmando que no es constitucional la no identificación entre la familia natural y la jurídica (STC 69/2007). 
nación no significa que los nuevos modelos familiares se puedan legitimar únicamente por el libre albedrío, al margen del Derecho, ni que pasen a ser necesariamente objeto de un tratamiento jurídicamente igualitario, ya que la extraordinaria complejidad de las relaciones que se desarrollan en ellos exigirá lógicamente una normativa específica.

\section{LA FAMILIA COMO CONTENIDO DEL DERECHO: LOS DERECHOS A LA FAMILIA Y A LA VIDA FAMILIAR}

El predominio de la voluntad sobre la estructura jurídica clásica a la hora de formar una familia ha desembocado en su afirmación como derecho humano de naturaleza personal, convirtiéndose así la familia en objeto y contenido del derecho en cuestión. El derecho a formar una familia parecería que tendría que conllevar necesariamente el derecho a la vida familiar, si bien el reconocimiento de cada uno de los derechos en preceptos separados presupone la no identidad plena en sus contenidos.

El derecho a formar una familia aparece reconocido junto al derecho a contraer matrimonio, entre otros preceptos citados en páginas anteriores, tanto en el CEDH (art. 12) como en la CIDH (art. 17.2). Ya hemos señalado que, pese a la literalidad de los enunciados, la aceptación social y jurídica de familias constituidas al margen del matrimonio permite individualizar el derecho en cuestión, de forma que el contenido del derecho a formar una familia implica la obligación de los poderes públicos de no obstaculizar con trabas y requisitos desproporcionados e injustificables la voluntad de las personas de constituir su propio ámbito familiar, cualquiera que sea la forma en la que quieran hacerlo dentro de un orden jurídico concreto. Buena parte de la jurisprudencia del TEDH a la que hemos hecho alusión en el apartado anterior, y a la que nos remitimos, viene referida precisamente a la construcción de este derecho.

El derecho de toda persona a su vida familiar tiene una proyección diferente. Su reconocimiento junto al derecho a la vida privada (arts. 8.1 $\mathrm{CEDH}$ y $11.2 \mathrm{CIDH}$ ) se concreta en la garantía del desarrollo de las relaciones interpersonales constituidas en el seno de la familia, en la medida en que afectan a los miembros de la misma no ya en su condición personal, sino, sobre todo, en su condición de integrantes del núcleo familiar, si bien, como veremos, el derecho no exige necesariamente convivencia.

A partir de los enunciados normativos se articula una jurisprudencia básicamente similar del TEDH y de la CIDH tanto sobre el derecho a la 
familia cuanto sobre el concepto y contenido del derecho a la vida familiar y su proyección en los distintos modelos de familia. La jurisprudencia de ambas Cortes evidencia el significado de la formulación de estos derechos en preceptos diferentes al dotar al derecho a la vida familiar de un contenido más amplio que el del derecho a formar una familia y relacionar las formas de vida familiar con los diferentes modelos de familia, en una interpretación extensiva de aquella.

La unión en los arts. $8 \mathrm{CEDH}$ y 11.2 CADH de los conceptos de derecho a la vida privada y familiar ha permitido a ambos tribunales ampliar generosamente el campo de aplicación y protección de ambos derechos $^{32}$, lo que permite afirmar su condición de creación jurisprudencial $^{33}$ en una proyección que se puede valorar como positiva, en la medida en que permite integrar como vida familiar supuestos fácticos vinculados a la vida personal de los integrantes en la relación familiar, a veces de forma muy tangencial. Como contrapartida se ha puesto de relieve que la vinculación de los dos derechos ha conducido a una dilatación del concepto vida familiar que puede terminar por ser un concepto confuso e indeterminado cuya identidad respecto de la vida privada puede llegar a diluirse ${ }^{34}$.

Por vida familiar se entiende la que deriva de la existencia de unas relaciones reales y suficientemente estrechas entre los miembros que integran una familia, constituida por el conjunto de personas unidas, bien por vínculos jurídicos de parentesco, bien por vínculos naturales o sentimentales no jurídicos, que participan de forma estable en una comunidad de vida. Se trata de un concepto abierto que posibilita el reconocimiento jurídico de la existencia de relaciones estrechas y estables que no se reducen a la sola convivencia, de forma que el derecho a la vida familiar no se extingue por el cese de la misma. Las relaciones familiares pueden así adoptar la forma de vida común en convivencia, de dependencia económica

32 S. Almeida, Familia a la luz del Convenio Europeo de Derechos Humanos, Lisboa, Juruá Editora, 2015, p. 74. El TEDH matiza ambos derechos en las dos Sentencias de 26 de junio de 2014 (casos Mennesson c. Francia y Labassee c. Francia) y en la de 21 de septiembre de 2016 (caso Foulon y Bouvet c. Francia), en las que niega la violación del derecho a la vida familiar de los padres de intención, pero reconoce la del derecho a la vida privada de los menores concernidos.

33 J. García Roca, H. Nogueira Alcalá y R. Bustos Gisbert, «La comunicación entre ambos sistemas...», op. cit., p. 74.

${ }^{34}$ F. SUDRE, «La "construction" par le juge européen du droit au respect de la vie familiale», en F. SUDRE (dir.), Le droit au respect de la vie familiale au sens de la Convention Européenne des Droits de l'Homme, Bruxelles, E. Bruylant, 2002, pp. 17-28. 
- como es normalmente el caso de los menores- o de relación afectiva, que englobaría supuestos tales como el derecho de visita a los hijos en el supuesto de cese de convivencia, relaciones entre padres e hijos extramatrimoniales, derechos de los padres condenados a penas de privación de libertad respecto de sus cónyuges e hijos, etcétera.

En definitiva, el derecho a la vida familiar se valora en relación con su función en la existencia de una persona, en la medida en que su objeto es la protección y estabilidad personal y emocional de los miembros de la familia, especialmente de los menores, aunque no solo de ellos, y ello al margen de que la familia en la que se desarrolla esta vida familiar no sea la convencional. Esa es la razón por la que este derecho se vincula con el libre desarrollo de la personalidad como despliegue de potencialidades psíquicas, morales, culturales, económicas y sociales de cada persona, y la conquista de los valores y los ideales que la satisfagan y atraigan ${ }^{35}$; proyecto en el que la integración en la familia y la participación en la vida familiar desempeñan un papel determinante.

En la paradigmática Sentencia de 13 de junio de 1979, caso Marchx c. Bélgica, el TEDH aborda tempranamente el concepto y el derecho a la vida familiar al considerar vida familiar la existente entre la madre soltera y su hija, que constituyen una familia monoparental no matrimonial que la legislación belga vigente en aquel momento no reconocía, ya que la filiación, en el caso de madres solteras, no quedaba determinada por el parto ${ }^{36}$. La sentencia concluye que la normativa belga, que se modificó posteriormente, era contraria al art. $8 \mathrm{CEDH}$, y no limita la conculcación a la relación madre-hija, sino que extiende el contenido del precepto a los vínculos entre parientes cercanos, que en la sentencia viene referido concretamente a la abuela materna, respecto de la que se negaba la existencia de cualquier vínculo familiar con la nieta extramatrimonial. La imposibilidad del reconocimiento jurídico de la existencia de vida familiar entre la abuela y la nieta suponía que ninguna de ellas podía acceder a los derechos económicos, jurídicos o asistenciales que les hubieran podido corresponder ${ }^{37}$, al margen de que pudiera existir entre ellas una convivencia de

35 J. Ruiz-Giménez Cortés e I. Ruiz-Giménez Arrieta, «Comentario al art. 10», en Ó. Alzaga Villaamil (dir.), Comentarios a la Constitución de 1978, Madrid, Edersa-Cortes Generales, 1997, p. 73.

${ }^{36}$ El nacimiento no establecía ningún lazo de parentesco entre madre e hija, que solo podría tener efecto, y de forma limitada, tras un complejo proceso jurídico.

37 Derechos de acción ante los tribunales, derechos de sucesión, asunción de la guardia y custodia o tutela, obligación subsidiaria de alimentos, etcétera. 
hecho. En palabras del tribunal, para el ordenamiento belga la nieta era respecto de su abuela «una extranjera».

A esta temprana sentencia seguirán un abultado número de resoluciones, tanto del Tribunal de Estrasburgo como de la Corte de San José, que abordarán el derecho a la vida familiar en manifestaciones bien diferentes.

En la Sentencia de 8 de diciembre de 1986, caso Johnston c. Irlanda, el TEDH resuelve la problemática del recurrente, que, al no admitirse el divorcio en Irlanda, se ve imposibilitado para legitimar al hijo habido con la mujer con la que convive y con la que no puede contraer matrimonio. El tribunal declara que dicha legislación vulnera el art. $8 \mathrm{CEDH}$ al imposibilitar la creación de lazos jurídicos familiares, lo que impide dar transcendencia jurídica a la vida familiar que de hecho tiene el recurrente con su compañera y su hijo. El TEDH ha mantenido una valoración similar del derecho, en sus distintas proyecciones, en su numerosa jurisprudencia, entre otras, los casos Keegan c. Irlanda (Sentencia de 26 de mayo de 1994) y Kroon c. Países Bajos (Sentencia de 27 de octubre de 1994).

En un escenario diferente, en la Sentencia de 22 de abril de 1997, caso $X, Y$ y $Z$ c. Reino Unido, el TEDH reconoce la configuración de una familia - y, en consecuencia, de vida familiar- por un transexual varón en su sexo adquirido, su pareja, del género femenino, y el hijo de la mujer concebido por inseminación artificial, indicando que al «decidir si una relación puede considerarse como "vida familiar" una serie de factores pueden ser relevantes, incluyendo si la pareja vive junta, la duración de su relación y si se ha demostrado el compromiso mutuo de tener hijos conjuntamente o por otros medios». En la misma línea, en la Sentencia de 24 de junio de 2010, caso Schalk y Kopf c. Austria, el TEDH determina que la noción de vida familiar abarca a una pareja del mismo sexo que convive en una relación estable de facto, considerando «artificial mantener una posición que sostenga que, a diferencia de una pareja heterosexual, una pareja del mismo sexo no puede disfrutar de una vida familiar en los términos del art. 8 del Convenio Europeo».

El mismo distanciamiento del modelo tradicional de familia mantiene la CIDH en la Sentencia de 24 de febrero de 2012, caso Atala Riffo y niñas c. Chile. El demandante reclama la tutela de sus tres hijas atribuida por los tribunales chilenos a la madre alegando que la familia que su exmujer ha constituido con otra mujer es nociva social y personalmente para sus hijas. La CIDH no rechaza el modelo tradicional de familia defendido por el padre, pero concluye que ni es exclusivo ni es el único válido, de forma que, constatada la integración de las niñas en la nueva familia constituida 
por la madre y su pareja femenina, considera arbitraria la interferencia del Estado en la vida privada de la recurrente, dado que la decisión judicial se fundó en prejuicios discriminatorios por su orientación sexual, privándola de su derecho a la vida familiar con sus hijas cuando era visible que se había constituido un núcleo familiar.

Otros aspectos específicos del derecho a la vida familiar en supuestos de no convivencia efectiva han sido valorados por el Tribunal de Estrasburgo. En la Sentencia de 21 de junio de 1988, caso Barrehab c. Países Bajos, el TEDH resuelve que el Gobierno debería haber tenido en cuenta en el momento de adoptar la medida de expulsión del demandante, residente ilegal en Holanda, separado y con una hija de catorce años respecto de la que tiene derecho de visita que ejerce regularmente, sus circunstancias personales, entre ellas la existencia de una vida familiar, consistente en aquel momento en el derecho de visita a su hija, que evidentemente se ve truncada. Concluye el tribunal con la precisión de las condiciones en que el art. 8 del Convenio puede interpretarse como límite a la posibilidad de expulsión de los extranjeros ${ }^{38}$. Este argumento ha sido reiterado por el TEDH en los supuestos de expulsión del recurrente ${ }^{39}$.

La vida familiar como derecho no se limita a los supuestos en los que se constata su existencia, sino que se llegará a incluir, de forma más o menos excepcional, la relación potencial que habría podido desarrollarse. Tal es el caso de la Sentencia de 10 de abril de 2012, caso K. A. B. c. España, en el que el TEDH incluye como vida familiar la intención de constituirla por parte del demandante, siendo su ausencia no imputable al mismo ${ }^{40}$. En otro contexto, pero con una decisión equiparable, la Sentencia de 28 de mayo de 1985, caso Abdulaziz, Cabales y Balkandali c. Reino Unido, en la que el TEDH aprecia vulneración del art. $8 \mathrm{CEDH}$ en la medida en que se impide la vida familiar de las recurrentes, con residencia legal en Reino Unido, a cuyos maridos se les niega el derecho de residencia, y, lo que a

38 P. Santolaya Machetti, El derecho a la vida familiar de los extranjeros, Valencia, Tirant lo Blanch-Instituto de Derecho Público, 2004, pp. 98 y ss., y M. SALES I JARDí, La vida familiar en la jurisprudencia del Tribunal Europeo de Derechos Humanos: una interpretación constructiva, Barcelona, Bosch, 2015, pp. 179-180.

39 SSTEDH de 26 de septiembre de 1997, caso Dalia c. Francia; de 29 de enero de 1997, caso Bouchelkia c. Francia; de 18 de febrero de 1991, caso Moustaquin c. Bélgica, y de 13 de febrero de 2001, caso Ezzooubi c. Francia.

${ }^{40}$ El denunciante, nigeriano, con un hijo de ocho meses no inscrito y cuya madre está en paradero desconocido, no puede demostrar su paternidad (no se le informa de la posible gratuidad de la prueba de paternidad). Al considerar al niño en situación de desamparo, las autoridades lo dan en acogida y posteriormente en adopción, pese a la oposición continua del padre, que ya se había hecho la prueba de paternidad demostrando que el hijo era suyo. 
nuestros efectos resulta más interesante, aprecia la misma vulneración en el caso del señor y la señora Cabales, que no estaban realmente casados aunque tenían el convencimiento de estarlo al haber celebrado una ceremonia que creían válida, ya que, afirma la sentencia, una familia proyectada y no consolidada puede bastar para incluirse en el nivel de protección del art. 8 .

La misma valoración potencial del derecho es la que aplica el TEDH en las dos sentencias sobre el mismo caso, Dickson c. Reino Unido, respecto del derecho a la vida familiar de los presos. En la primera (18 de abril de 2006), el Tribunal se basa en el margen de apreciación nacional para estimar no contrario al CEDH la no inclusión del derecho a las visitas conyugales o vis a vis de los presos ${ }^{41}$. Posteriormente, la Gran Sala dicta la Sentencia de 4 de abril de 2007 en la revisión del caso y modifica el criterio anterior, entendiendo que la visita conyugal forma parte de la vida familiar de los presos, lo que obliga al Estado a garantizar de alguna forma el mantenimiento de la vida familiar de las personas internas en centros penitenciarios.

Como todos los derechos, el derecho a la vida familiar tiene sus límites, y una de las causas principales de su posible limitación es la presencia de menores y de su interés superior, lo que se refleja en reiterada jurisprudencia. La STEDH de 30 de noviembre de 2010, caso P. V. c. España, valida la restricción del régimen de visitas del padre a la hija menor, que era el único elemento constitutivo de la vida familiar de aquel tras el divorcio, no por causa del posterior cambio de sexo del padre, sino por la inestabilidad emocional que dicho cambio provocó en la menor, cuyo interés superior se superpone al derecho del padre.

Una serie de resoluciones jurisdiccionales abordan otro aspecto de conflicto que puede suscitarse entre el interés superior del menor y el derecho que comentamos en un campo especialmente sensible, que es el que tiene lugar en los supuestos de situaciones de desamparo de menores, no solo por la presencia de menores afectados, sino también porque se abordan situaciones que con frecuencia son irreversibles respecto de la limitación, a veces total, del derecho a la vida familiar. Haremos únicamente referencia a dos resoluciones del Tribunal de Estrasburgo.

La STEDH de 26 de octubre de 2006, caso Wallova y Walla c. la República Checa, concluye con la condena al Estado checo por vulneración del art. $8 \mathrm{CEDH}$, entendiendo que las autoridades se extralimitaron con las

${ }^{41}$ El recurrente, en prisión, solicita la posibilidad de que su mujer se someta a un tratamiento de reproducción asistida, siendo él el donante, ya que la duración de su condena, la edad de la mujer y la inexistencia de visitas vis a vis impedirían cualquier otra forma de procreación. 
medidas de acogimiento de los hijos menores del matrimonio demandante cuando lo que existía era una carencia de medios económicos de los padres, y lo que se debería haber hecho, y no se hizo, era haberles prestado algún tipo de ayuda material para que pudieran superar sus dificultades antes de adoptar la decisión drástica y totalmente inadecuada de acogimiento, que se adoptó sin ninguna valoración del riesgo que suponía para el derecho a la vida familiar tanto de los padres como de los hijos ${ }^{42}$.

La situación que plantea el caso Saleck Bardi c. España (STEDH de 24 de mayo de 2011) supondrá la pérdida definitiva del derecho a la vida familiar de la demandante. El TEDH condena a España por la pasividad de las autoridades españolas (servicios sociales y órganos jurisdiccionales) que permiten que transcurran seis años desde que se plantea la situación que da origen al conflicto, con lo que las consecuencias del mismo son ya irremediables al estar una menor afectada. Al no haberse adoptado con mayor rapidez las medidas conducentes a reunir a la menor con su madre, aquella se insertó de forma definitiva en la familia de acogida lo que se tradujo en que el interés superior de la menor obligó al TEDH a resolver que no cambiase su estatus, pese a la evidencia de que el Estado había vulnerado el derecho a la vida familiar de la madre, incluso aunque esta, por el bien de su hija, hubiese renunciado a la vida familiar a la que tenía derecho ${ }^{43}$.

\section{LA FAMILIA COMO TITULAR DEL DERECHO: EL DERECHO A LA INTIMIDAD FAMILIAR}

El reconocimiento del derecho a la intimidad familiar supone identificar a la familia como su titular, lo que parece vincularle al derecho a la vida familiar aunque no son derechos idénticos. En textos constitucionales e internacionales se puede encontrar la consagración del derecho a la vida familiar y a su protección, además del derecho a la intimidad personal, que no tiene por qué estar vinculada de forma necesaria a la vida en fami-

42 Ante la situación de paro del padre, los servicios públicos checos no solo decidieron el acogimiento de los cinco hijos, sino que los separaron en dos familias de acogida.

${ }^{43}$ La menor, residente con su madre en un campamento de refugiados argelinos, llega a España con diez años en una estancia de verano con una familia española. La estancia se prolonga y la madre reclama su vuelta, pero los servicios sociales aprecian situación de desamparo y el juez otorga la custodia y posterior tutela, pese a que la madre siempre recurrió las distintas resoluciones judiciales. 
lia, aunque ha sido uno de los motores de buena parte de la construcción jurisprudencial respecto de determinados aspectos de la vida familiar. Por el contrario, no son demasiados los textos que consagran explícitamente el derecho a la intimidad familiar como un derecho autónomo.

El derecho a la intimidad familiar no tiene una formulación expresa ni en el CEDH ni en la CADH, más allá de las fórmulas incluidas en los respectivos arts. 8 y 11.2 para garantizar la no injerencia en la «vida privada [de las personas] y en la de su familia», entre las que se encuentran los derechos tradicionales de inviolabilidad del domicilio y correspondencia, y, en los términos del $\mathrm{CADH}$, los ataques ilegales a la honra y reputación. Es también difícil encontrar este derecho en las constituciones, y en este sentido se puede considerar paradigmático el art. 18.1 de la Constitución española, que lo incluye por primera vez en nuestro ordenamiento y que garantiza, junto al derecho al honor y a la propia imagen, «el derecho a la intimidad personal y familiar». La inclusión conjunta de ambos derechos y la mayor generalización del reconocimiento del derecho a la intimidad personal exige hacer una primera valoración de la misma ${ }^{44}$.

La construcción de la intimidad personal hay que plantearla a partir de la identificación de intimidad personal con vida privada ${ }^{45}$. En la medida en que la vida privada implique capacidad de autodeterminación como capacidad de decidir sin injerencias ajenas sobre los diferentes ámbitos vitales que conforman la personalidad del individuo, es posible asumir aquella identificación, en cuanto compendio de la privacy acuñada por la jurisprudencia norteamericana, como el «derecho a ser dejado solo», «a no ser molestado», a vivir la vida personal con el mínimo de interferencias o injerencias ajenas y no queridas.

Este sentido de intimidad como autonomía personal ha sido reiteradamente invocado por la jurisprudencia del TEDH a la hora de fundamentar buena parte de las resoluciones referidas a la orientación sexual de los demandantes (a las que hemos hecho alusión en páginas anteriores), lo que no deja de ser lógico en la medida en que el fundamento de la intimidad personal se encuentra en la dignidad y en el derecho al libre desarro-

${ }^{4}$ P. Santolaya MachetTI, «Derecho a la vida privada y familiar: un contenido notablemente ampliado del derecho a la intimidad (art. 8 CEDH)», en J. García Roca y P. SANTOLAYA (dirs.), La Europa de los derechos. El Convenio Europeo de Derechos Humanos, Madrid, Centro de Estudios Políticos y Constitucionales, 2009, pp. 429-436.

${ }^{45}$ M. LEZERTUA, «El derecho a la vida privada y familiar en la jurisprudencia del Tribunal Europeo de Derechos Humanos», en Perfiles del Derecho constitucional a la vida privada y familiar, Madrid, Consejo General del Poder Judicial, 1996, pp. 52 y ss. 
llo de la personalidad ${ }^{46}$, articulándose a su servicio una serie de derechos fundamentales, como son la inviolabilidad de domicilio, el secreto de las comunicaciones, la libertad ideológica y religiosa, la libertad de expresión de pensamiento, etcétera.

Otra proyección es la intimidad como «reserva», lo que se quiere excluir del conocimiento público ${ }^{47}$. Este concepto se fundamenta también en la autodeterminación, pero de forma matizada, ya que hay que vincularla con la consideración del margen de decisión que pueda tener una persona para incluir en su intimidad los hechos que no quiere que salgan a la luz pública. Podría pensarse que, en aras del derecho a la intimidad personal, esta es una decisión que compete únicamente al afectado en la que no caben injerencias ajenas, pero esta posición implica el riesgo que supone la variabilidad del ámbito de exclusión, lo que nos lleva a la consideración de que el significado de la privacy, reflejo de una posición liberal frente al Estado con un sentido claramente individualista, es hoy insuficiente tanto frente a la sociedad de la información ${ }^{48}$ como en relación con las pautas sociales imperantes, en la medida en que son ellas las que determinan lo que la sociedad entiende que puede considerarse invasión del ámbito íntimo de una persona ${ }^{49}$. Al no ser el ámbito de privacidad exclusivamente personal, son aquellas pautas sociales las que proyectan una cierta objetividad a la hora de determinar cuál es el «nivel mínimo de vida digna», lo que lo convierte en un criterio dinámico y mudable que es necesario adecuar a la específica situación personal del titular del derecho.

El derecho a la intimidad familiar responde a la proyección de la intimidad en la familia como ámbito primario de desarrollo de la personalidad, a cuyo servicio se articula el derecho en cuestión, que responde a la prohibición de injerencias arbitrarias o abusivas en las relaciones constituidas en el seno familiar, lo que se vincula también con la decisión de determinar ámbitos de exclusión del conocimiento público relativo a datos, personales o familiares, en función de su afectación concreta al núcleo

${ }^{46} \mathrm{El} \mathrm{TC}$ afirma que «sin el derecho a la intimidad no es realizable la dignidad que a la persona humana le corresponde» (STC 20/1992).

47 Las SSTC 73/1982 y 231/1988 se refieren, respectivamente, a «un ámbito o reducto en el que se veda que otros penetren» y de «un ámbito propio y reservado frente a la acción y conocimiento de los demás».

${ }_{48}$ Entre otras, la STEDH de 2 de agosto de 1984, caso Malone, y la STC 114/1984.

49 J. Pardo Falcón, «Comentario al art. 18», en M. E. CaSAS BaAmonde y M. Rodríguez-Piñero y Bravo Ferrer (dirs.), Comentarios a la Constitución de 1978. XXX Aniversario, Madrid, Fundación Wolters Kluwer, 2008, pp. 421-422. 
familiar. La titularidad del derecho, a diferencia del derecho a la intimidad personal, recae en la familia como institución, desde el momento en que la prohibición de injerencias viene referida a la familia como unidad. No cabe duda de que también afecta a los miembros de la misma, pero no en su condición de personas individualmente consideradas, sino en su condición de integrantes del núcleo familiar.

El TEDH ha desarrollado una interesante jurisprudencia sobre la que ha articulado el derecho a la intimidad familiar en su significado de prohibición de injerencias ajenas y no queridas en la vida familiar, centrada de manera especial, hoy por hoy, en la valoración del impacto de determinadas agresiones medioambientales en la vida familiar de los denunciantes, de tal forma que podría considerarse que con ella ha construido una vertiente específica del derecho (intimidad personal y familiar en el ámbito domiciliario) no consagrada normativamente de forma específica ${ }^{50}$. Son paradigmáticas las sentencias de los casos Powell y Rainer c. Reino Unido (21 de febrero de 1990), López Ostra c. España (9 de diciembre de 1994), Guerra y otros c. Italia (19 de febrero de 1998), Moreno Gómez c. España (16 de noviembre de 2004) o Martínez Martínez c. España (18 de octubre de 2011). En todas ellas el tribunal aprecia que la agresión medioambiental (ruidos de aviones, malos olores o ruidos excesivos de actividades, incluso autorizadas por los órganos públicos correspondientes) cerca del domicilio supone una vulneración del derecho a la intimidad familiar, consecuente con el derecho a la vida familiar ${ }^{51}$.

La proyección del derecho a la intimidad familiar como exclusión del conocimiento público de hechos sensibles para la familia ha sido objeto de resoluciones de los órganos jurisdiccionales tanto nacionales como supranacionales, si bien no siempre se ha conseguido individualizarle de forma nítida respecto de la vertiente de la intimidad personal. A este respecto nos vamos a referir a algunas sentencias del Tribunal Constitucional español de las que se puede deducir algún criterio para identificar la intimidad familiar frente a la personal. En la STC 115/2000, de 10 de mayo, el tribunal considera que un reportaje publicado en una revista en el que una antigua niñera de los hijos de una persona con notoriedad pública revela datos sobre su vida familiar, sin relevancia pública y cuya veracidad resulta irrelevante a juicio del tribunal, ha vulnerado el derecho a la inti-

50 Ibid., pp. 422-423.

51 El TEDH valora el medio ambiente como parte de la intimidad familiar, lo que conlleva la obligación de los poderes públicos de garantizar los elementos que lo integran, ya que la contaminación medioambiental vulnera aquel derecho en cualquier caso. 
midad familiar, ya que los datos en cuestión no se referían solo a los hábitos personales de la recurrente en amparo, sino también a sus relaciones y costumbres familiares, entendiendo el tribunal que la niñera, al tener acceso a la vida familiar de la recurrente, tenía implícitamente el deber de secreto profesional.

El argumento es similar en dos sentencias, SSTC 197/1991, de 17 de octubre, y 134/1999, de 15 de julio, en respuesta a dos recursos de amparo interpuestos por los mismos recurrentes, personas de notoriedad pública, y por hechos similares: la publicación de datos referidos al origen y filiación biológica de los dos hijos menores adoptados. De nuevo valora el tribunal la tensión entre la libertad de información y del derecho a la intimidad familiar a favor de esta última, incluso aunque la información publicada sea veraz y aunque los padres adoptivos hubiesen publicitado en ruedas de prensa la adopción de sus hijos, como efectivamente habían hecho. La filiación y la identificación del origen biológico de los adoptados forma parte del ámbito propio y reservado que configura su derecho a la intimidad personal, derecho que se extiende también a la intimidad de las personas con las que tienen un vínculo familiar, que se ven afectadas así en su derecho a la intimidad familiar, no personal. De las tres sentencias mencionadas, pero de forma específica de estas dos últimas, dadas las actividades publicitarias realizadas por los mismos padres de los menores, se deduce que el ámbito de protección de la intimidad familiar mantiene su máximo nivel de garantía, incluso a pesar de los actos de disposición de sus propios titulares ${ }^{52}$.

Concluimos con la STC 231/1988, de 2 de diciembre, en la que el tribunal, en respuesta al amparo solicitado por la demandante, viuda de un torero, contra la comercialización de un vídeo que incluía unas imágenes del marido en la enfermería de la plaza de toros, rechaza los argumentos de vulneración del derecho a la intimidad del marido, pero aprecia, sin embargo, la vulneración del derecho a la intimidad familiar de la viuda y sus familiares.

En todos los fallos mencionados se aprecia tanto la estrecha relación que existe entre intimidad personal e intimidad familiar como su diferencia. La primera es un derecho personalísimo, mientras que la dimensión familiar de la intimidad exige su extensión a la de todos los que comparten una relación familiar ${ }^{53}$. Esto supone que es la familia como tal quien

52 J. Pardo Falcón, «Comentario al art. 18», op. cit., p. 422.
53 P. Santolaya Machetti, El derecho a la vida familiar.., op. cit., p. 17.

Foro, Nueva época, vol. 21, núm. 2 (2018): 195-221 
resulta directamente afectada por el hecho lesivo, porque, como afirma la STC 231/1988, «esa intimidad no es solo la propia del directamente afectado, sino que, por su repercusión moral, es también derecho de sus familiares».

La vinculación estrecha entre las dos proyecciones de la intimidad no hace fácil la tarea de individualizarlas, pero, a nuestro juicio, la titularidad de la familia del derecho a su intimidad tiene entidad suficiente como para que la jurisprudencia de los diferentes tribunales pudiera definir su contenido propio.

\section{CONCLUSIONES}

Este artículo no tiene conclusiones. No tiene más pretensión que la de describir someramente algunos factores que han actuado como motor de cambios de naturaleza cualitativa que se proyectan en la transformación de elementos, hasta hace poco incuestionables, de una de las instituciones que sigue siendo un núcleo básico de la sociedad, la familia, respecto de las que no hemos tenido otra pretensión que exponer, a grandes rasgos, su proceso de su mutación en derecho humano cuya articulación de todas sus derivadas está todavía en construcción. Estamos tan inmersos en un proceso evolutivo constante, avasallador y perentorio que probablemente los árboles no nos dejen ver el bosque. En uno de esos árboles hemos fijado nuestra atención.

Pero, por supuesto, este artículo lo que sí tiene es un propósito y una motivación. Participo con estas líneas en el recuerdo de un compañero, el profesor José Antonio Alonso de Antonio, con el que he compartido cerca de cuarenta años en las lides del Derecho constitucional, en una relación presidida siempre por la cordialidad, el respeto y el afecto.

\section{ABREVIATURAS}

ATC Auto del Tribunal Constitucional español.

CADH Convención Americana de Derechos Humanos.

CDFUE Carta de Derechos Fundamentales de la Unión Europea.

CE Constitución española de 1978.

CEDH Convenio Europeo de Derechos Humanos.

CEPC Centro de Estudios Políticos y Constitucionales. 
CIDH Corte Interamericana de Derechos Humanos.

LO Ley Orgánica.

SCIDH Sentencia de la Corte Interamericana de Derechos Humanos.

STC Sentencia del Tribunal Constitucional.

STEDH Sentencia del Tribunal Europeo de Derechos Humanos.

TC Tribunal Constitucional.

TEDH Tribunal Europeo de Derechos Humanos.

TJUE Tribunal de Justicia de la Unión Europea.

TUE Tratado de la Unión Europea. 